\title{
Niacin increased glucose, insulin, and C-peptide levels in sedentary nondiabetic postmenopausal
} women

\section{Yunsuk Koh'}

Heidi Bidstrup ${ }^{2}$

David L Nichols ${ }^{2}$

'Department of Health, Human Performance, and Recreation, Baylor University, Waco, TX, USA; ${ }^{2}$ Department of Kinesiology, Texas Woman's University, Denton, TX, USA
This article was published in the following Dove Press journal:

International Journal of Women's Health

23 October 2014

Number of times this article has been viewed

Abstract: The current study examined the effects of niacin and a single bout of aerobic exercise on plasma glucose, insulin, and C-peptide in sedentary, nondiabetic postmenopausal women. As a crossover design, 17 participants underwent four different trials: rest during the no-niacin condition (R), exercise during the no-niacin condition (E), rest during the with-niacin condition $(\mathrm{RN})$, and exercise during the with-niacin condition (EN). All participants took 1,000 mg/day of extended-release niacin for 4 weeks during the with-niacin conditions (RN and EN). The exercise treatment consisted of a single bout of treadmill walking at $60 \%$ heart rate reserve until $400 \mathrm{kcal}$ were expended. Blood samples were collected at 24 hours after each trial and analyzed for changes in plasma glucose, insulin, and C-peptide. A two by two analysis of variance was used to examine the changes in dependent variables, and the Bonferroni adjustment was employed as the post hoc test. The level of statistical significance was set at $P<0.05$. There was no significant interaction between exercise and niacin, nor was there a main effect of exercise for changes in glucose, insulin, or C-peptide. However, there was a significant main effect for niacin as mean glucose, insulin, and C-peptide values significantly increased with niacin; glucose increased $10.6 \%(P=0.001)$, from $95.03 \pm 10.67 \mathrm{mg} / \mathrm{dL}$ to $105.07 \pm 13.56 \mathrm{mg} / \mathrm{dL}$; insulin increased $61.8 \%$ $(P=0.001)$, from $16.98 \pm 12.49 \mu \mathrm{U} / \mathrm{mL}$ to $27.48 \pm 14.84 \mu \mathrm{U} / \mathrm{mL}$; and C-peptide increased $46.1 \%$ $(P=0.001)$, from $1.65 \pm 0.75 \mathrm{ng} / \mathrm{mL}$ to $2.41 \pm 0.97 \mathrm{ng} / \mathrm{mL}$. Although niacin was generally well tolerated, given its adverse effects on glucose, insulin, and C-peptide profiles, the use of niacin should be done so with caution and under medical supervision.

Keywords: Niaspan, exercise, lipids and lipoproteins, hyperglycemia

\section{Introduction}

Genetic and environmental factors such as aging, obesity, physical inactivity, and poor diet are associated with glucose intolerance, insulin resistance, and impaired insulin sensitivity, which contribute to the development of type 2 diabetes mellitus (T2DM), a disease with both societal and healthcare implications. ${ }^{1-3}$ Aerobic exercise may positively influence glucose and insulin metabolism by lowering plasma glucose and insulin, while increasing glucose uptake and insulin sensitivity. ${ }^{4}$ In particular, postmenopausal women who have increased risk factors for developing cardiovascular disease (CVD) and T2DM due to physiological changes associated with menopause may benefit from aerobic exercise. ${ }^{5}$

Niacin, a B vitamin, has been widely recommended for the treatment of dyslipidemia since it can significantly increase high-density lipoprotein cholesterol (HDL-C) and decrease triglycerides and low-density lipoprotein cholesterol. ${ }^{6-11}$ Both immediateand extended-release (ER) formula of niacin can effectively modify blood lipids and
Correspondence: Yunsuk Koh Performance, and Recreation, Baylor University, One Bear Place \#973 I3,

Waco, TX 76798, USA

Tel +l 2547104002

Fax +I 2547103527

Email yunsuk_koh@baylor.edu 
lipoproteins, which in turn reduce CVD risk factors. ${ }^{7,12}$ However, compliance to the immediate-release formula of niacin is relatively low due to its adverse side effects, such as flushing, itching, or swelling and can include the instability in glucose homeostasis, which may result in the termination of niacin therapy and/or changes in diabetic medication dosages. ${ }^{7}$ In contrast, the ER formula of niacin is relatively well tolerated, with minimum side effects and appears to positively alter blood lipids and lipoproteins..$^{8,10,12-14}$ Despite its beneficial effects on lipid and lipoprotein metabolism, niacin may cause some negative effects on glucose and insulin metabolism by exacerbating glucose control and insulin sensitivity that can further lead to hyperglycemia. ${ }^{10,15}$

Given the positive effects of aerobic exercise on glucose regulation ${ }^{16-18}$ and niacin on lipid and lipoprotein profiles, ${ }^{9,11,14,19}$ niacin combined with aerobic exercise could yield a synergetic effect on glucose and lipid metabolism, and possibly be prescribed as a treatment plan for postmenopausal women, who have elevated risk factors for CVD or T2DM. Improving lipid profiles in this population could lower risk factors for CVD and metabolic syndrome, thus decreasing the risk of developing glucose intolerance, insulin resistance, and/or T2DM. Therefore, the current study examined if the ER formula of niacin $(1,000 \mathrm{mg} /$ day $)$ and a single bout of moderate intensity aerobic exercise (400 kcal) would positively affect glucose, insulin, and C-peptide profiles in sedentary, nondiabetic postmenopausal women.

\section{Materials and methods Participants}

Sedentary, nondiabetic postmenopausal women between the ages of 40 and 80 years were solicited via flyers and an advertisement in the local newspaper. Inclusion criteria for the study were as follows: a) have been postmenopausal at least 1 year (naturally or surgically), b) have not been on hormone replacement therapy, c) have no known heart or organ disease, d) have no diabetes mellitus, e) have not taken any medications that alter the levels of glucose, insulin, C-peptide, lipids, or lipoproteins, g) have not smoked or quit within the past 6 months, and h) have not participated in regular physical activity (three or more times per week, at least 20 minutes per session). In addition to meeting the aforementioned requirements, each participant abstained from partaking in any form of physical activity (aerobic and anaerobic) and was encouraged to maintain their normal diet throughout the duration of participation in the study. Upon acceptance into the study, each participant signed informed consent, filled out a medical history questionnaire, and received permission from a personal physician to participate. The methods and procedures for the current study were reviewed and approved by the Institutional Review Board.

\section{Exercise testing}

The participants performed a submaximal exercise test on a treadmill (Quinton Instruments, Bothell, WA, USA) to determine the appropriate exercise intensity for $60 \%$ heart rate reserve (HRR). The submaximal exercise test began with a warm-up stage for 2 minutes at $0 \%$ grade with the speed of $3.0 \mathrm{mph}$. After the warm-up, the grade increased by $2.0 \%$ every 2 minutes, while the speed remained at $3.0 \mathrm{mph}$ until the participants reached their $60 \%$ HRR. The $60 \%$ HRR was calculated by subtracting the resting heart rate (HR) from the age-estimated maximum HR (220 - age), and this value was then multiplied by $60 \%$ (the $\%$ exercise intensity for the current study), followed by adding the resting HR. In equation form, it is as follows: ${ }^{20}$

$$
\begin{aligned}
60 \% \mathrm{HRR}= & {[(220-\text { age })-\text { resting } \mathrm{HR}] \times 60 \% } \\
& + \text { resting } \mathrm{HR}
\end{aligned}
$$

During the submaximal exercise test, 12-lead electrocardiograph (ECG), HR, blood pressure, and the ratings of perceived exertion were recorded. HR and 12-lead ECG were continuously monitored during the submaximal exercise test via a Quinton Q4500 12-lead ECG (Quinton Instruments). Blood pressure and ratings of perceived exertion using the 6-20 Borg's scale were recorded at the end of each stage. To determine the energy expenditure of $400 \mathrm{kcal}$, expired respiratory gases were collected using the Parvo Medics Truemax 2400 metabolic measurement system (Consentius Technologies, Sandy, UT, USA) at three different time points (beginning, middle, and the end of submaximal exercise test) for 15 minutes each. However, only the last 10 minutes of expired gases for each time point were analyzed to determine the average oxygen consumption $\left(\mathrm{VO}_{2}\right)$, which later was used to determine total energy expenditure using a thermal equivalents table of oxygen for respiratory exchange ratio. ${ }^{21}$

\section{Study design}

Due to the known potential side effects, all participants were first assigned to the no-niacin condition followed by the with-niacin condition for 4 weeks. During the no-niacin and with-niacin conditions, both rest and exercise trials were randomly assigned to each condition (rest during the noniacin condition $[\mathrm{R}]$, exercise during the no-niacin condition $[\mathrm{E}]$, rest during the with-niacin condition [RN], and exercise 
during the with-niacin condition [EN]). Each participant completed each of the four trials (see Figure 1). The exercise trial consisted of performing a single bout of aerobic exercise at $60 \%$ HRR on the treadmill until $400 \mathrm{kcal}$ were expended, whereas the participants did not perform any exercise during the rest trial. At least 1 week between the rest and exercise trials within the no-niacin and with-niacin conditions was required to avoid any effects the last bout of exercise might have on glucose, insulin, and C-peptide.

\section{Body composition assessment}

Body composition was assessed by a Lunar DPX-IQ dualenergy x-ray absorptiometer (Lunar, Madison, WI, USA). During the assessment, participants lay supine, fully clothed, on a padded table for the scan. All X-ray scans were conducted by a licensed X-ray technician.

\section{Niacin supplements}

After completing the no-niacin condition, the participants began with the with-niacin condition, where they received the ER formula of niacin (Niaspan; Kos Pharmaceuticals, Miami, FL, USA) tablets, which were labeled by trial week and placed in plastic bags. To reach a target dosage of $1,000 \mathrm{mg} /$ day, the participants began with one $250 \mathrm{mg}$ dose of niacin/day (Slo-Niacin; Upsher-Smith Laboratory, Minneapolis,
$\mathrm{MN}$, USA) during the first week of the with-niacin condition since the lowest dosage of Niaspan available was $500 \mathrm{mg}$. During the second week of the with-niacin condition, the dosage of niacin was increased to $500 \mathrm{mg} /$ day. The participants ingested $1,000 \mathrm{mg}$ of niacin/day for 4 weeks thereafter (from third to sixth week). To minimize the possible side effects, the participants were allowed to ingest a $325 \mathrm{mg}$ aspirin or a $200 \mathrm{mg}$ ibuprofen 30 minutes prior to administering the niacin if needed.

\section{Blood analysis}

The participants arrived at the laboratory after the minimum of 10 hours of fasting in the morning between $6.00 \mathrm{am}$ and 8.00 am to have blood drawn at 24 hours after the completion of each trial (R, E, RN, and EN). Upon arrival, the participants rested in a chair for 20 minutes, and venous blood samples were collected into an ethylenediaminetetraacetic acid (EDTA) plasma tube and a serum separator tube. The EDTA plasma sample was gently mixed and centrifuged at 3,000 rpm for 20 minutes to separate plasma. The serum blood sample remained at room temperature for 20 minutes to be clotted, and was then centrifuged $(3,000 \mathrm{rpm})$ at $4^{\circ} \mathrm{C}$ for 20 minutes to separate serum. Plasma and serum samples were allocated into microcentrifuge tubes and immediately frozen at $-80^{\circ} \mathrm{C}$ for the further biochemical analyses.

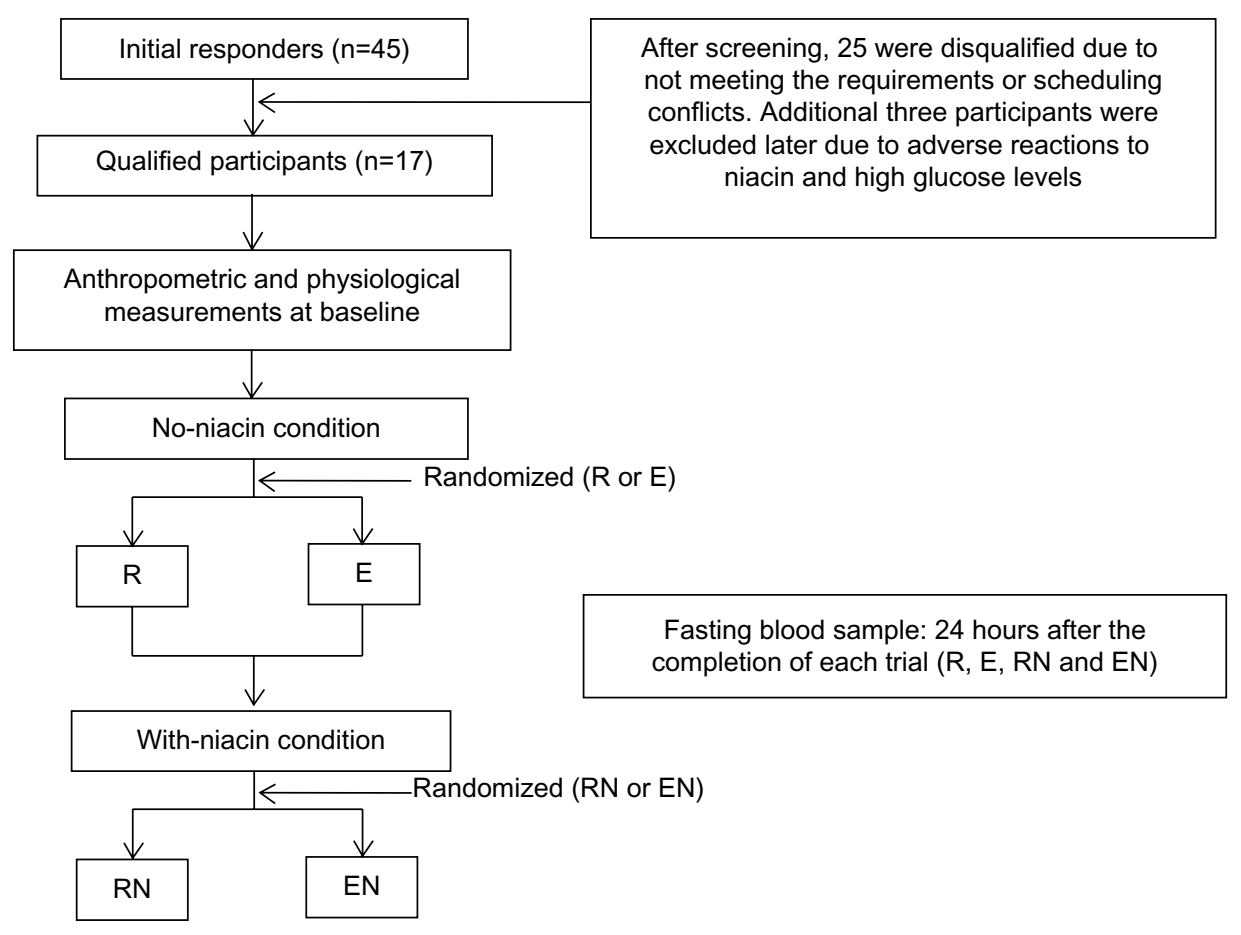

Figure I Study design flow chart.

Abbreviations: $\mathrm{E}$, exercise during the no-niacin condition; EN, exercise during the with-niacin condition; R, rest during the no-niacin condition; RN, rest during the withniacin condition. 
Plasma samples were used in the analysis of glucose (Glucose UV reagent \#R84682; Raichem, San Diego, CA, USA). Serum samples were used in the analyses of insulin (Insulin ELISA \#DSL-10-1600; Diagnostic Systems Laboratories, Inc., Webster, TX, USA) and C-peptide (C-peptide ELISA \#DSL-10-7000; Diagnostic Systems Laboratories, Inc.). Each assay procedure was performed as instructed by each assay protocol, and the optical density was measured using a PowerWave ${ }^{\mathrm{TM}}$ XS microplate spectrophotometer (Bio Tek Instruments, Winooski, VT, USA). The intraassay coefficient of variations for glucose, insulin, and C-peptide were $1.70 \%$, $6.40 \%$, and $4.50 \%$, respectively. The interassay coefficient of variations were $1.90 \%, 4.70 \%$, and $8.40 \%$ for glucose, insulin, and C-peptide, respectively. The concentrations of glucose, insulin, and C-peptide were corrected, if necessary, for any postexercise plasma volume changes using the Dill and Costill equation. ${ }^{22}$

\section{Statistical analysis}

Changes in glucose, insulin, and C-peptide were determined by a two (conditions: no-niacin and with-niacin) by two (trials: rest or exercise) analysis of variance (ANOVA), and the Bonferroni adjustment was used as the post hoc test. All statistical analyses were performed using the Statistical Package for Social Sciences 19.0 (SPSS Inc., Chicago, IL, USA). The data are reported as mean \pm standard deviation. The level of statistical significance was set at $P<0.05$.

\section{Results}

Of the 45 applicants who initially responded to the advertisement for this study, 25 were disqualified due to not meeting the study criteria or scheduling conflicts. Twenty qualified participants volunteered for the study, but three participants were excluded due to the following reasons: 1) two participants dropped out prior to the completion of the study due to the adverse reactions of itching, flushing, and/or swelling, which occurred during the 1,000 mg dosage of niacin; 2) one participant completed the study, but was later found to have abnormally high glucose values ( $>126 \mathrm{mg} / \mathrm{dL})$. Therefore, the remaining 17 participants were included in the final data analysis. The baseline measurements of the participants are presented in Table 1. Fasting plasma volumes for rest and exercise trials were not different; therefore, no correction was made for plasma volume change.

Four weeks of niacin therapy consisting of $1,000 \mathrm{mg} /$ day resulted in a statistically significant increase $(P=0.001)$ in glucose, insulin, and C-peptide (Table 2). The mean value of fasting glucose for the no-niacin condition
Table I Anthropometric and physiological characteristics of participants at baseline

\begin{tabular}{lcll}
\hline & Mean \pm SD & Minimum & Maximum \\
\hline Age (years) & $57.6 \pm 7.5$ & 46.0 & 71.0 \\
Height $(\mathrm{cm})$ & $160.1 \pm 7.0$ & 147.0 & 171.4 \\
Weight $(\mathrm{kg})$ & $77.2 \pm 14.8$ & 57.5 & 115.4 \\
BMI & $30.1 \pm 4.8$ & 21.1 & 39.3 \\
Body fat (\%) & $47.0 \pm 6.2$ & 34.1 & 55.6 \\
Postmenopausal status & $13.7 \pm 7.9$ & 2.0 & 28.0 \\
(years) & & & \\
WHR & $0.8 \pm 0.03$ & 0.8 & 0.9 \\
HR rest $($ bpm) & $71.2 \pm 9.7$ & 60.0 & 96.0 \\
HR (bpm) & $163.5 \pm 6.5$ & 149.0 & 174.0 \\
$60 \%$ HRR (bpm) & $134.1 \pm 6.2$ & 118.0 & 141.0 \\
Total exercise time (min) & $61.6 \pm 9.0$ & 45.0 & 80.0 \\
to expend 400 kcal & & & \\
\hline
\end{tabular}

Notes: All values are expressed as mean \pm standard deviation (SD). $\mathrm{HR}_{\max }=(220$ - age $) . H R R=\left(\left[H R_{\text {max }}-H R_{\text {rest }}\right] \times\right.$ intensity + HRrest $)$.

Abbreviations: $\mathrm{BMl}$, body mass index; $\mathrm{HR}_{\text {max }}$, age-estimated maximum heart rate; $H R_{\text {ress }}$, resting heart rate; $H R R$, heart rate reserve; $W H R$, waist to hip ratio.

was $95.03 \pm 10.67 \mathrm{mg} / \mathrm{dL}$, but this value increased to $105.07 \pm 13.56 \mathrm{mg} / \mathrm{dL}$ (or $10.6 \%$ ) after the 4 weeks of niacin therapy. Fasting insulin for the no-niacin condition was $16.98 \pm 12.49 \mu \mathrm{U} / \mathrm{mL}$ and increased by $61.8 \%$ $(27.48 \pm 14.84 \mu \mathrm{U} / \mathrm{mL})$ with niacin. The mean value for fasting C-peptide for the no-niacin condition was $1.65 \pm 0.75 \mathrm{ng} / \mathrm{mL}$, and increased to $2.41 \pm 0.97 \mathrm{ng} / \mathrm{mL}$ (or $46.1 \%$ ) with niacin. However, the main effect for exercise or the interactions for niacin and exercise was not significant for any dependent variables as shown in Tables 3 and 4, respectively.

\section{Discussion}

The present study investigated the independent and combined effects of niacin (1,000 mg/day for 4 weeks) and a single bout of aerobic exercise ( $60 \%$ HRR) on glucose, insulin, and C-peptide profiles in sedentary, nondiabetic, postmenopausal women. The effects of niacin and exercise on lipids and lipoproteins have been previously reported elsewhere. ${ }^{13}$ In brief, niacin increased both $\mathrm{HDL}-\mathrm{C}$ and $\mathrm{HDL}_{2}-\mathrm{C}$ and lowered the total cholesterol to HDL-C ratio. The primary finding of the present study was that niacin increased glucose, insulin, and C-peptide in nondiabetic, postmenopausal women.

Table 2 The main effects of niacin on glucose, insulin, and C-peptide

\begin{tabular}{lccl}
\hline & No niacin & With niacin & $P$ \\
\hline Glucose $(\mathrm{mg} / \mathrm{dL})$ & $95.03 \pm 10.67$ & $105.07 \pm 13.56$ & $0.00 I^{*}$ \\
Insulin $(\mu \mathrm{U} / \mathrm{mL})$ & $16.98 \pm 12.49$ & $27.48 \pm 14.84$ & $0.00 I^{*}$ \\
C-peptide $(\mathrm{ng} / \mathrm{mL})$ & $1.65 \pm 0.75$ & $2.4 I \pm 0.97$ & $0.00 I^{*}$ \\
\hline
\end{tabular}

Notes: All values are expressed as mean \pm standard deviation; * represents significant difference between the no-niacin and with-niacin conditions. 
Table 3 The main effects of exercise on glucose, insulin, and C-peptide

\begin{tabular}{lccl}
\hline & Rest & Exercise & $P$ \\
\hline Glucose $(\mathrm{mg} / \mathrm{dL})$ & $101.68 \pm 14.04$ & $98.43 \pm 14.43$ & 0.115 \\
Insulin $(\mu \mathrm{U} / \mathrm{mL})$ & $21.04 \pm 12.99$ & $18.37 \pm 10.19$ & 0.079 \\
C-peptide $(\mathrm{ng} / \mathrm{mL})$ & $2.10 \pm 1.10$ & $1.96 \pm 0.94$ & 0.087
\end{tabular}

Note: All values are expressed as mean \pm standard deviation.

The niacin-induced increase in glucose observed in the present study is consistent with the results from other studies. ${ }^{6,12,14,23,24}$ Similar to the current study, glucose increased up to $7.0 \%$ from baseline values after participants (men and women with hypercholesterolemia) took $1,000 \mathrm{mg} /$ day of niacin for 96 weeks. ${ }^{6}{ }^{14}$ Chang et $\mathrm{al}^{24}$ have reported that 2 weeks of niacin therapy increased fasting glucose levels, with the largest increase seen in the older impaired glucose tolerance group. In contrast, some studies have reported no changes or a decrease in glucose with niacin therapy. ${ }^{8,10,11,25,26}$ In one study, glucose levels decreased from baseline in nonobese, healthy, physically active men and women with normal glucose tolerance during 4 hours of continuous intravenous infusion of niacin. ${ }^{26}$ Fasting glucose levels were not significantly changed after 4 months of niacin therapy in men (43-69 years old) with T2DM or impaired fasting glucose who took a niacin dosage of 2,000 mg/day. ${ }^{11}$ Elam et $\mathrm{al}^{25}$ have reported that niacin therapy of up to 60 weeks initially increased glucose in patients with controlled T2DM, but the increased glucose values returned to baseline with continued therapy. In addition, Goldberg et $\mathrm{al}^{8}$ and Grundy et $\mathrm{a}^{10}$ found initial increases in fasting blood glucose, but by the conclusion of the studies, the increased glucose values had returned to baseline values. Findings by Goldberg et $\mathrm{al}^{8}$ were similar to the current study, in that the $1,000 \mathrm{mg}$ /day dose caused a significant increase (5.4\%) in fasting glucose concentrations from baseline in men and women (21-75 years old). However, the similarity ends at an increased dosage $(3,000 \mathrm{mg} /$ day $)$, where fasting glucose levels decreased by $0.4 \%$ from baseline. The turnaround in glucose values could be attributed to a long duration of therapy (up to 60 weeks) because disturbances in glucose values associated with a niacin therapy have been found to resolve after several weeks of niacin therapy. Grundy et a ${ }^{10}$ also found minimal changes in fasting glucose values during a 16-week trial involving male and female patients with T2DM who took $1,000 \mathrm{mg}$ or $1,500 \mathrm{mg} /$ day of niacin. These changes were usually seen during the $1,500 \mathrm{mg} /$ day dose but were negligible and not statistically significant. The overall lack of change in glucose values is credited to adjustments made in diabetic medications for the patients taking the higher dose. Although the exact mechanism by which niacin incurs mild hyperglycemia has not been clearly understood, it may be associated with a niacin-induced decrease in insulin sensitivity, which is caused by a rebound in plasma free fatty acids following niacin ingestion. ${ }^{27}$

In the current study, niacin increased insulin from baseline by $61.8 \%$, which is consistent with other studies. ${ }^{24,28}$ A significant increase in fasting insulin levels as well as a significant decrease in insulin sensitivity were observed during 2,000 $\mathrm{mg}$ of niacin therapy for 2 weeks in healthy men and women. ${ }^{24}$ This niacin-induced increase in insulin may be attributed to aging and the impairment of $\beta$-cell compensation to insulin resistance..$^{24}$ According to Kahn et al, ${ }^{28} 2$ weeks of niacin administration caused fasting insulin levels to double, insulin sensitivity to decrease, and insulin resistance to develop in young, healthy men. However, Alvarsson and Grill ${ }^{29}$ reported that 14 days of niacin therapy did not significantly alter insulin in healthy, nonobese men and women (25-61 years old) without diabetes. In addition, a short duration of niacin therapy (14 days) did not significantly change mean fasting insulin levels in healthy, nonobese men and women, possibly due to low dosage of niacin $(500 \mathrm{mg}$ /day for 7 days and 1,000 mg/day for 7 days). ${ }^{30}$ The inconsistent results observed between the present and aforementioned studies may be due to the different characteristics of the study population such as age, body mass index (BMI), and physical activity levels. For instance, the average age in the Alvarsson and Grill study ${ }^{29}$ that showed no change in insulin levels with niacin was 45 years, with $23.9\left(\mathrm{~kg} / \mathrm{m}^{2}\right)$ BMI, whereas the average age of participants in the present study was 58 years, with $30.1\left(\mathrm{~kg} / \mathrm{m}^{2}\right)$ BMI. Aging is associated

Table 4 The interaction of niacin and exercise on glucose, insulin, and C-peptide

\begin{tabular}{lllcrr}
\hline & R & E & RN & EN & P \\
\hline Glucose $(\mathrm{mg} / \mathrm{dL})$ & $96.58 \pm I 1.39$ & $93.48 \pm 12.98$ & $106.77 \pm 14.89$ & $103.37 \pm 14.47$ & 0.941 \\
Insulin $(\mu \mathrm{U} / \mathrm{mL})$ & $15.62 \pm 9.25$ & $13.19 \pm 4.96$ & $26.46 \pm 14.18$ & $23.54 \pm 11.53$ & 0.945 \\
C-peptide $(\mathrm{ng} / \mathrm{mL})$ & $1.67 \pm 0.95$ & $1.63 \pm 0.84$ & $2.52 \pm 1.11$ & $2.29 \pm 0.95$ & 0.506 \\
\hline
\end{tabular}

Note: All values are expressed as mean \pm standard deviation.

Abbreviations: $\mathrm{E}$, exercise during the no-niacin condition; $\mathrm{EN}$, exercise during the with-niacin condition; R, rest during the no-niacin condition; RN, rest during the withniacin condition. 
with $\beta$-cell dysfunction, insulin resistance, and an increase in visceral fat, resulting in an increase in BMI. Differences may also be attributed to the level of physical activity since inactivity could contribute to the insulin resistance incurred during niacin therapy.

Niacin significantly increased C-peptide by $46.1 \%$ in the current study. In contrast to the present study, some studies have reported no changes in C-peptide with niacin therapy in healthy, nonobese men and women. ${ }^{29,31} \mathrm{C}$-peptide levels are nearly parallel with insulin levels, which can be expected since C-peptide is released in equimolar amounts to insulin. Though the exact mechanisms are not fully understood, free fatty acids are believed to play a role in the secretion of insulin and C-peptide. In a study by Dobbins et al, ${ }^{31}$ insulin levels significantly changed without changes in C-peptide levels, which suggests a change in insulin clearance occurred rather than a change in the rate of insulin secretion.

Exercise may positively influence metabolic risk factors including glucose and insulin profiles. ${ }^{4,32}$ In the current study, however, a single bout of aerobic exercise did not significantly lower glucose, insulin, or C-peptide. This finding is consistent with other studies. ${ }^{33-35}$ Baynard et $\mathrm{al}^{33}$ reported single or multiple bouts of moderate intensity aerobic exercise $\left(60 \%\right.$ peak attainable $\left.\mathrm{VO}_{2}\right)$ did not alter glucose or insulin in sedentary, obese women with T2DM. One hour walking exercise for 24 weeks (3 days/week) at 60\%-70\% maximum $\mathrm{VO}_{2}$ did not alter glucose or insulin levels in moderately-obese, postmenopausal women, even though there were significant decreases in mean body weight, BMI, and percent body fat. ${ }^{34}$ Multiple bouts of aerobic exercise in obese, postmenopausal women with T2DM also resulted in no significant change in fasting glucose levels. ${ }^{35}$ The lack of change in glucose or insulin levels following acute or chronic exercise performed at moderate intensity may indicate that a higher intensity level is required to effectively modify glucose and insulin. In contrast to the current study, several investigations involving repeated bouts of aerobic exercise reported changes in glucose and insulin. ${ }^{3,36}$ Mean plasma glucose levels decreased without any changes in mean fasting insulin levels in sedentary, postmenopausal women, who expended $1,500 \mathrm{kcal}$ per week while exercising at $65 \%$ maximum $\mathrm{VO}_{2}{ }^{3}{ }^{3}$ A possible explanation for the decrease in mean glucose levels in the aforementioned study was the total amount of calories expended, which was almost four times as much as the current study, and lasted for 15 weeks. Acute bouts of exercise at moderate intensity requiring a caloric expenditure of $1,500 \mathrm{kcal} /$ week may be required as minimal requirements to improve CVD risk factors. ${ }^{3}$ Insulin levels were decreased about 30\% with aerobic exercise in obese, young men and women (26-42 years old) who followed a training program of 1 hour, 3 days/week for 6 weeks. ${ }^{37}$ In another training study, fasting insulin levels at 24 hours postexercise in healthy men and women (30-37 years old) decreased $8.0 \%$, and insulin sensitivity increased by $10 \%$. However, this improvement was short lived, reverting to baseline values after 72 hours. ${ }^{16}$ After a single bout of moderate or high intensity exercise, insulin sensitivity improved by $51 \%$ and $85 \%$, respectively, in middle-aged prediabetic adults, and there was no difference between moderate and high intensity exercise sessions. ${ }^{38}$ An acute bout of exercise decreased the levels of insulin and C-peptide in middle-aged, nonobese and obese nondiabetic women but not in obese T2DM women. However, the exercise-induced increase in insulin returned to baseline level during recovery. Interestingly, the level of insulin during recovery increased above the resting value in obese, nondiabetic and diabetic women, ${ }^{39}$ indicating that obese individuals may have a slower rate of glucose clearance than their nonobese counterparts.

\section{Conclusion}

Although the use of niacin has often been recommended for the treatment of dyslipidemia, further study may be necessary to determine the safety and efficacy of its use in sedentary, postmenopausal women, especially those with T2DM given the increased frequency seen in persons of 60 years of age and older. Future clinical studies examining the effects of niacin alone or combined with aerobic exercise should entail a protocol of several months, possibly resulting in an improved metabolic response given that the increases in glucose caused by niacin therapy may return to baseline levels after a few months. Given the adverse effects of niacin, the use of niacin in postmenopausal women should proceed with caution under medical supervision until further investigations are conducted.

\section{Acknowledgment}

This study was supported by Texas Woman's University Institutional Grant.

\section{Disclosure}

The authors report no conflicts of interest in this work.

\section{References}

1. Lorber D. Importance of cardiovascular disease risk management in patients with type 2 diabetes mellitus. Diabetes Metab Syndr Obes. 2014;7:169-183.

2. Schellenberg ES, Dryden DM, Vandermeer B, Ha C, Korownyk C. Lifestyle interventions for patients with and at risk for type 2 diabetes: a systematic review and meta-analysis. Ann Intern Med. 2013;159(8):543-551. 
3. Asikainen TM, Miilunpalo S, Kukkonen-Harjula K, et al. Walking trials in postmenopausal women: effect of low doses of exercise and exercise fractionization on coronary risk factors. Scand J Med Sci Sports. 2003;13(5):284-292.

4. Roberts CK, Little JP, Thyfault JP. Modification of insulin sensitivity and glycemic control by activity and exercise. Med Sci Sports Exerc. 2013;45(10):1868-1877.

5. Souza HC, Tezini GC. Autonomic cardiovascular damage during post-menopause: the role of physical training. Aging Dis. 2013;4(6): 320-328.

6. Capuzzi DM, Guyton JR, Morgan JM, et al. Efficacy and safety of an extended-release niacin (Niaspan): a long-term study. Am J Cardiol. 1998;82(12A):74U-81U; discussion 85U-86U.

7. Goldberg AC. A meta-analysis of randomized controlled studies on the effects of extended-release niacin in women. Am J Cardiol. 2004;94(1):121-124.

8. Goldberg A, Alagona P Jr, Capuzzi DM, et al. Multiple-dose efficacy and safety of an extended-release form of niacin in the management of hyperlipidemia. Am J Cardiol. 2000;85(9):1100-1105.

9. Grundy SM, Mok HY, Zech L, Berman M. Influence of nicotinic acid on metabolism of cholesterol and triglycerides in man. J Lipid Res. 1981;22(1):24-36.

10. Grundy SM, Vega GL, McGovern ME, et al; Diabetes Multicenter Research Group. Efficacy, safety, and tolerability of once-daily niacin for the treatment of dyslipidemia associated with type 2 diabetes: results of the assessment of diabetes control and evaluation of the efficacy of niaspan trial. Arch Intern Med. 2002;162(14):1568-1576.

11. Vega GL, Cater NB, Meguro S, Grundy SM. Influence of extendedrelease nicotinic acid on nonesterified fatty acid flux in the metabolic syndrome with atherogenic dyslipidemia. Am J Cardiol. 2005;95(11): 1309-1313.

12. Knopp RH, Alagona P, Davidson M, et al. Equivalent efficacy of a time-release form of niacin (Niaspan) given once-a-night versus plain niacin in the management of hyperlipidemia. Metabolism. 1998;47(9) 1097-1104.

13. Koh Y, Ben-Ezra V, Biggerstaff KD, Nichols DL. Responses of blood lipids and lipoproteins to extended-release niacin and exercise in sedentary postmenopausal women. J Gerontol A Biol Sci Med Sci. 2010;65(9):924-932.

14. Guyton JR, Goldberg AC, Kreisberg RA, Sprecher DL, Superko HR, O'Connor CM. Effectiveness of once-nightly dosing of extendedrelease niacin alone and in combination for hypercholesterolemia. Am J Cardiol. 1998;82(6):737-743.

15. Pieper JA. Overview of niacin formulations: differences in pharmacokinetics, efficacy, and safety. Am J Health Syst Pharm. 2003; 60(13 Suppl 2):S9-S14; quiz 25.

16. Boulé NG, Weisnagel SJ, Lakka TA, et al; HERITAGE Family Study. Effects of exercise training on glucose homeostasis: the HERITAGE Family Study. Diabetes Care. 2005;28(1):108-114.

17. Ekelund U, Franks PW, Sharp S, Brage S, Wareham NJ. Increase in physical activity energy expenditure is associated with reduced metabolic risk independent of change in fatness and fitness. Diabetes Care. 2007;30(8):2101-2106.

18. Healy GN, Dunstan DW, Salmon J, et al. Objectively measured lightintensity physical activity is independently associated with 2-h plasma glucose. Diabetes Care. 2007;30(6):1384-1389.

19. Poynten AM, Gan SK, Kriketos AD, et al. Nicotinic acid-induced insulin resistance is related to increased circulating fatty acids and fat oxidation but not muscle lipid content. Metabolism. 2003;52(6):699-704.

20. Thompson WR, Gordon NF, Pescatello LS, editors. ACSM's Guidelines for Exercise Testing and Prescription. 8th ed. Baltimore, MD: Lippincott Williams \& Wilkins; 2010.
21. McArdle WD, Katch FI, Katch VL. Sports and Exercise Nutrition. Baltimore, MD: Lippincott Williams \& Wilkins; 2012.

22. Dill DB, Costill DL. Calculation of percentage changes in volumes of blood, plasma, and red cells in dehydration. JAppl Physiol. 1974;37(2): 247-248.

23. Molnar GD, Berge KG, Rosevear JW, McGuckin WF, Achor RW. The effect of nicotinic acid in diabetes mellitus. Metabolism. 1964;13: 181-190.

24. Chang AM, Smith MJ, Galecki AT, Bloem CJ, Halter JB. Impaired beta-cell function in human aging: response to nicotinic acid-induced insulin resistance. J Clin Endocrinol Metab. 2006;91(9):3303-3309.

25. Elam MB, Hunninghake DB, Davis KB, et al. Effect of niacin on lipid and lipoprotein levels and glycemic control in patients with diabetes and peripheral arterial disease: the ADMIT study: A randomized trial. Arterial Disease Multiple Intervention Trial. JAMA. 2000;284(10): 1263-1270.

26. Landau C, Chen YD, Skowronski R, Hollenbeck CB, Jaspan JB, Reaven GM. Effect of nicotinic acid on plasma glucose concentration in normal individuals. Horm Metab Res. 1992;24(9):424-428.

27. Gille A, Bodor ET, Ahmed K, Offermanns S. Nicotinic acid: pharmacological effects and mechanisms of action. Annu Rev Pharmacol Toxicol. 2008;48:79-106.

28. Kahn SE, Beard JC, Schwartz MW, et al. Increased beta-cell secretory capacity as mechanism for islet adaptation to nicotinic acid-induced insulin resistance. Diabetes. 1989;38(5):562-568.

29. Alvarsson M, Grill V. Impact of nicotinic acid treatment on insulin secretion and insulin sensitivity in low and high insulin responders. Scand J Clin Lab Invest. 1996;56(6):563-570.

30. Kelly JJ, Lawson JA, Campbell LV, et al. Effects of nicotinic acid on insulin sensitivity and blood pressure in healthy subjects. J Hum Hypertens. 2000;14(9):567-572.

31. Dobbins RL, Chester MW, Daniels MB, McGarry JD, Stein DT. Circulating fatty acids are essential for efficient glucose-stimulated insulin secretion after prolonged fasting in humans. Diabetes. 1998;47(10): 1613-1618.

32. Fretts AM, Howard BV, McKnight B, et al. Modest levels of physical activity are associated with a lower incidence of diabetes in a population with a high rate of obesity: the strong heart family study. Diabetes Care. 2012;35(8):1743-1745.

33. Baynard T, Franklin RM, Goulopoulou S, Carhart R Jr, Kanaley JA. Effect of a single vs multiple bouts of exercise on glucose control in women with type 2 diabetes. Metabolism. 2005;54(8):989-994.

34. Fox AA, Thompson JL, Butterfield GE, Gylfadottir U, Moynihan S, Spiller G. Effects of diet and exercise on common cardiovascular disease risk factors in moderately obese older women. Am J Clin Nutr. 1996;63(2):225-233.

35. Giannopoulou I, Ploutz-Snyder LL, Carhart R, et al. Exercise is required for visceral fat loss in postmenopausal women with type 2 diabetes. J Clin Endocrinol Metab. 2005;90(3):1511-1518.

36. Magkos F, Tsekouras Y, Kavouras SA, Mittendorfer B, Sidossis LS. Improved insulin sensitivity after a single bout of exercise is curvilinearly related to exercise energy expenditure. Clin Sci (Lond). 2008; 114(1):59-64.

37. Björntorp P, Holm G, Jacobsson B, et al. Physical training in human hyperplastic obesity. IV. Effects on the hormonal status. Metabolism. 1977;26(3):319-328.

38. Rynders CA, Weltman JY, Jiang B, et al. Effects of exercise intensity on postprandial improvement in glucose disposal and insulin sensitivity in prediabetic adults. J Clin Endocrinol Metab. 2014;99(1):220-228.

39. Krotkiewski M, Górski J. Effect of muscular exercise on plasma C-peptide and insulin in obese non-diabetics and diabetics, type II. Clin Physiol. 1986;6(6):499-506. 
International Journal of Women's Health

Dovepress

\section{Publish your work in this journal}

The International Journal of Women's Health is an international, peer- a very quick and fair peer-review system, which is all easy to use. reviewed open-access journal publishing original research, reports, editorials, reviews and commentaries on all aspects of women's healthcare including gynecology, obstetrics, and breast cancer. The Visit http://www.dovepress.com/testimonials.php to read real quotes from published authors.

manuscript management system is completely online and includes

Submit your manuscript here: http://www.dovepress.com/international-journal-of-womens-health-journal 